\title{
Human factors and usability of an incentive spirometer patient reminder (SpiroTimer ${ }^{\mathrm{TM}}$ )
}

\begin{abstract}
Introduction: To address the problem of incentive spirometry (IS) noncompliance, a use-tracking IS reminder device (SpiroTimer ${ }^{\mathrm{TM}}$ ) was developed. In a recent randomized clinical trial, the SpiroTimer ${ }^{\mathrm{TM}}$ improved IS use compliance, length of stay, and mortality. For successful, safe, and effective implementation of a new medical device, human factors and usability must be evaluated. This study aims to evaluate the SpiroTimer ${ }^{\mathrm{TM}}$ 's human factors as they pertain to intended users, use environments, and uses.

Material and methods: Immediately following the completion of the randomized clinical trial of the SpiroTimer ${ }^{\mathrm{TM}}$, before the providers were informed of the results of the study, a human factors and usability survey was distributed in-person to all nurses involved in the trial. Variations in nurse user perspectives were evaluated.

Results: A total of 52 nurses (100\% response rate) completed the survey. In general, most nurses felt IS use compliance is poor (65\%; 34/52, $p=0.0265$ ) and should be improved (94\%; 49/52, $\mathrm{p}<0.001)$. Nurses agreed the SpiroTimer ${ }^{\mathrm{TM}}$ ameliorated patient IS use compliance (82\%; 41/50, p < 0.001), IS effectiveness (74\%; 37/50, p < 0.001), and patient engagement in their own care $(88 \% ; 44 / 50, p<0.001)$. Nurses reported the SpiroTimer ${ }^{\text {TM }}$ helped remind them to work with their patients on IS $(70 \% ; 35 / 50, p$ $=0.0047)$ while reducing the number of times they had to remind their patients to use their IS $(70 \% ; 35 / 50, p=0.0047)$. They felt that they would use the SpiroTimer ${ }^{\mathrm{TM}}$ with all their patients $(82 \% ; 41 / 50, p<0.001)$ and that they would recommend the

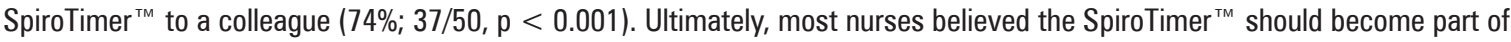
routine patient care $(78 \% ; 39 / 50, \mathrm{p}<0.001)$.

Discussion: For a new medical technology to a medical device to be effectively implemented, human factors and usability must be demonstrated. Nurses believe the clinically effective SpiroTimer ${ }^{\mathrm{TM}}$ helps both patients and nurses and should become part of routine care.
\end{abstract}

Key words: incentive spirometry, human factors, innovation, SpiroTimer, respiratory

Adv Respir Med. 2020; 88: 574-579

\section{Introduction}

Incentive spirometry (IS) is commonly prescribed to reduce respiratory complications [1-3]. IS (Figure 1) works by expanding alveoli through maximal inspiration to prevent atelectasis. Poor patient compliance is known to hinder the effectiveness of IS [3-5].

To address the problem of IS noncompliance, a use-tracking IS reminder device (SpiroTimer ${ }^{\mathrm{TM}}$ ) was developed and clinically tested in a recent large randomized clinical trial [6]. The SpiroTimer ${ }^{\mathrm{TM}}$ utilizes a bell to remind the patient to use the
IS, a sensor to detect a use, and a timestamp recorder to track IS use. In the recent randomized controlled trial published in JAMA Surgery [6], patients undergoing coronary artery bypass grafting surgery were randomized to receive the SpiroTimer ${ }^{\mathrm{TM}}$ with the reminder bell turned off or on. Those with the bell turned on were found to have improved IS compliance, reduced mean atelectasis severity scores, lowered patient length of stay at the hospital, and reduced six-month mortality [6]. In other words, the SpiroTimer ${ }^{\mathrm{TM}}$ demonstrated significant cost- and life-saving benefits. 
For successful, safe, and effective implementation of a new medical device, such as the SpiroTimer $^{\mathrm{TM}}$, human factors and usability must be evaluated. As described by the FDA, human factors "focuse on the interactions between people and devices" [7], including how people perceive, interpret, and manipulate the device. Nurses play a major role in IS implementation [5]. This study aims to evaluate the SpiroTimer ${ }^{\mathrm{TM}}$ 's human factors as they pertain to intended users, use environments, and uses.

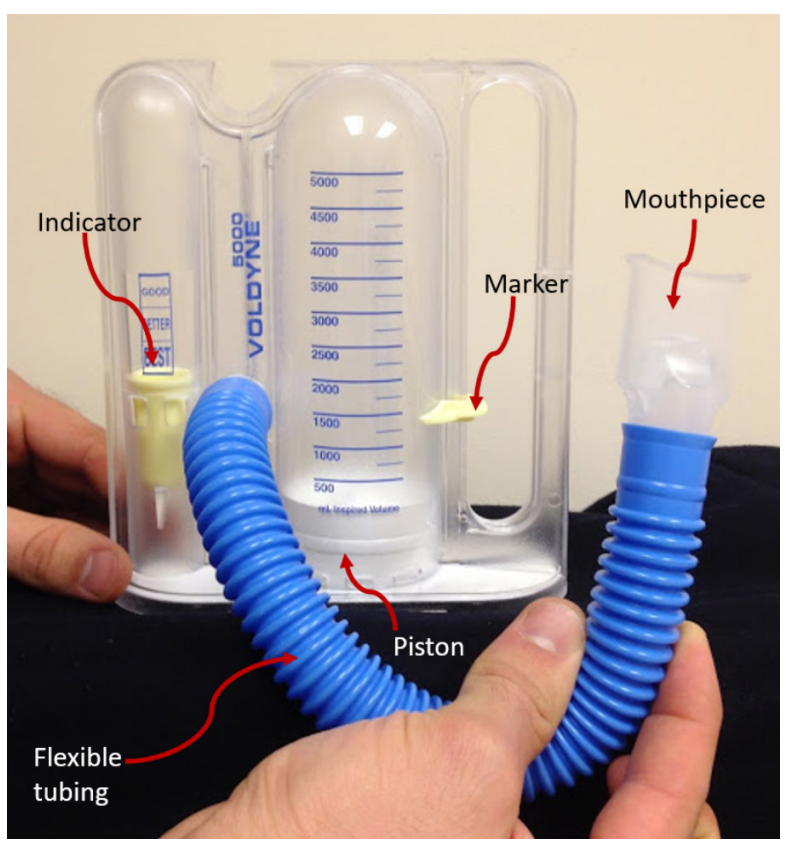

Figure 1. Incentive spirometer

\section{Material and methods}

The data collection for the SpiroTimer ${ }^{\mathrm{TM}}$ randomized clinical trial was completed in December 2017. Immediately following the trial, in January 2018, a survey regarding SpiroTimer ${ }^{\mathrm{TM}}$ human factors and usability was distributed in-person to the nurses involved in the trial. The nurses and the investigator handing out the surveys were blinded to the results of the study. Survey questions utilized a six-point Likert scale format. Statistical analysis was done using Chi-squared tests for comparative statistics with Bonferroni correction for a significant $\mathrm{p}$ value $<0.008$.

\section{Results}

There were 52 unique respondents (100\% response rate). Most nurses felt that IS compliance is poor $(65 \% ; 34 / 52, p=0.0265)$ and that IS compliance should be improved (94\%; 49/52, $\mathrm{p}<0.001$ ) (Table 1).

Most nurses felt the SpiroTimer ${ }^{\mathrm{TM}}$ improved IS use compliance $(82 \% ; 41 / 50, \mathrm{P}<0.001)$. The nurses also felt that the SpiroTimer ${ }^{\mathrm{TM}}$ improved IS effectiveness $(74 \%$; 37/50, $p<0.001)$, as well as patient engagement in their own care (88\%; 44/50, $\mathrm{p}<0.001)$. Most healthcare professionals felt that the SpiroTimer ${ }^{\mathrm{TM}}$ improved pulmonary/respiratory function $(74 \% ; 37 / 50$, p $<0.001$ ) and helped to reduce post-operative pulmonary complications $(68 \% ; 34 / 50, \mathrm{p}=$ 0.0109) (Table 2).

\section{Table 1. Nurse's perspectives on IS compliance}

\begin{tabular}{|c|c|c|c|c|c|}
\hline & Agreement & Answer options (score) & \multicolumn{2}{|c|}{ Aggregated \% (n)/52 } & $\mathbf{P}$ \\
\hline \multirow{7}{*}{$\begin{array}{l}\text { In general, patient IS } \\
\text { use compliance } \\
\text { is poor }\end{array}$} & \multirow[t]{3}{*}{ Agree } & Strongly agree (2) & $3.85 \%$ & \multirow[t]{3}{*}{$65.38 \%(34)$} & 0.0265 \\
\hline & & Agree (10) & $19.23 \%$ & & \\
\hline & & Somewhat agree (22) & $42.31 \%$ & & \\
\hline & \multirow[t]{3}{*}{ Disagree } & Somewhat disagree (9) & $17.31 \%$ & \multirow[t]{3}{*}{$34.62 \%(18)$} & \\
\hline & & Disagree (9) & $17.31 \%$ & & \\
\hline & & Strongly disagree (0) & $0 \%$ & & \\
\hline & Agreement & Answer options (score) & \multicolumn{2}{|c|}{ Aggregated \% (n)/52 } & $\mathbf{p}$ \\
\hline \multirow{6}{*}{$\begin{array}{l}\text { In general, patient IS } \\
\text { use compliance should } \\
\text { be improved }\end{array}$} & \multirow[t]{3}{*}{ Agree } & Strongly agree (6) & $11.54 \%$ & \multirow[t]{3}{*}{$94.23 \%(49)$} & $<0.001$ \\
\hline & & Agree (27) & $51.92 \%$ & & \\
\hline & & Somewhat agree (16) & $30.77 \%$ & & \\
\hline & \multirow[t]{3}{*}{ Disagree } & Somewhat disagree (2) & $3.85 \%$ & \multirow[t]{3}{*}{$5.77 \%(3)$} & \\
\hline & & Disagree (1) & $1.92 \%$ & & \\
\hline & & Strongly disagree (0) & $0 \%$ & & \\
\hline
\end{tabular}

IS - incentive spirometry 
Table 2. Impact of SpiroTimer ${ }^{\mathrm{TM}}$

\begin{tabular}{|c|c|c|c|c|c|}
\hline \multirow{3}{*}{$\begin{array}{l}\text { Overall, the reminder improved } \\
\text { patient IS use compliance }\end{array}$} & \multirow{2}{*}{$\frac{\text { Agreement }}{\text { Agree }}$} & \multirow{2}{*}{$\begin{array}{c}\text { Answer options (score) } \\
\text { Strongly agree (3) }\end{array}$} & \multicolumn{2}{|c|}{ Aggregated \% (n)/50 } & \multirow{2}{*}{$\frac{\mathbf{p}}{<0.001}$} \\
\hline & & & $6 \%$ & $82 \%(41)$ & \\
\hline & & Agree (17) & $34 \%$ & & \\
\hline & & Somewhat agree (21) & $42 \%$ & & \\
\hline & Disagree & Somewhat disagree (8) & $16 \%$ & $18 \%(9)$ & \\
\hline & & Disagree (1) & $2 \%$ & & \\
\hline & & Strongly disagree (0) & $0 \%$ & & \\
\hline \multirow{6}{*}{$\begin{array}{l}\text { Overall, the reminder improved } \\
\text { IS effectiveness }\end{array}$} & Agree & Strongly agree (2) & $4 \%$ & $74 \%(37)$ & $<0.001$ \\
\hline & & Agree (13) & $26 \%$ & & \\
\hline & & Somewhat agree (22) & $44 \%$ & & \\
\hline & Disagree & Somewhat disagree (12) & $24 \%$ & $26 \%(13)$ & \\
\hline & & Disagree (1) & $2 \%$ & & \\
\hline & & Strongly disagree $(0)$ & $0 \%$ & & \\
\hline \multirow{6}{*}{$\begin{array}{l}\text { The reminder improved patient } \\
\text { engagement in their own care }\end{array}$} & Agree & Strongly agree (2) & $4 \%$ & $88 \%(44)$ & $<0.001$ \\
\hline & & Agree (16) & $32 \%$ & & \\
\hline & & Somewhat agree (26) & $52 \%$ & & \\
\hline & Disagree & Somewhat disagree (4) & $8 \%$ & $12 \%(6)$ & \\
\hline & & Disagree (2) & $4 \%$ & & \\
\hline & & Strongly disagree (0) & $0 \%$ & & \\
\hline \multirow{6}{*}{$\begin{array}{l}\text { The reminder helped improve } \\
\text { pulmonary/respiratory function }\end{array}$} & Agree & Strongly agree (1) & $2 \%$ & $74 \%(37)$ & $<0.001$ \\
\hline & & Agree (16) & $32 \%$ & & \\
\hline & & Somewhat agree (20) & $40 \%$ & & \\
\hline & Disagree & Somewhat disagree (11) & $22 \%$ & $26 \%(13)$ & \\
\hline & & Disagree (2) & $4 \%$ & & \\
\hline & & Strongly disagree (0) & $0 \%$ & & \\
\hline \multirow{6}{*}{$\begin{array}{l}\text { The reminder helped reduce } \\
\text { postoperative pulmonary } \\
\text { complications (e.g., atelectasis, } \\
\text { pneumonia). }\end{array}$} & Agree & Strongly agree (0) & $0 \%$ & $68 \%(34)$ & 0.011 \\
\hline & & Agree (11) & $22 \%$ & & \\
\hline & & Somewhat agree (23) & $46 \%$ & & \\
\hline & Disagree & Somewhat disagree (10) & $20 \%$ & $32 \%(16)$ & \\
\hline & & Disagree (6) & $12 \%$ & & \\
\hline & & Strongly disagree $(0)$ & $0 \%$ & & \\
\hline \multirow{6}{*}{$\begin{array}{l}\text { The reminder helped patients } \\
\text { to correctly use their IS. }\end{array}$} & Agree & Strongly agree (0) & $0 \%$ & $56 \%(28)$ & 0.3961 \\
\hline & & Agree (9) & $18 \%$ & & \\
\hline & & Somewhat agree (19) & $38 \%$ & & \\
\hline & Disagree & Somewhat disagree (13) & $26 \%$ & $44 \%(22)$ & \\
\hline & & Disagree (8) & $16 \%$ & & \\
\hline & & Strongly disagree (1) & $2 \%$ & & \\
\hline
\end{tabular}

Most nurses agreed that the SpiroTimer ${ }^{\mathrm{TM}}$ reduced the amount of times they had to remind patients to use their IS (70\%; 35/50, $\mathrm{p}=0.0047$ ), and that the SpiroTimer ${ }^{\mathrm{TM}}$ helped the nurses work with their patients on IS $(70 \% ; 35 / 50, p=0.0047)$.
Most nurses found the SpiroTimer ${ }^{\mathrm{TM}}$ to be helpful (72\%; 36/50, p = 0.0018) (Table 3).

Nurses reported the SpiroTimer ${ }^{\mathrm{TM}}$ directly addresses patients who forget to use there IS (96.08\%; 49/51, p < 0.001), who do not use it fre- 
Table 3. Impact of SpiroTimer ${ }^{\mathrm{TM}}$ implementation

\begin{tabular}{|c|c|c|c|c|c|}
\hline \multirow{4}{*}{$\begin{array}{l}\text { Overall, the reminder reduced } \\
\text { the number of times I had to } \\
\text { remind patients to use their IS }\end{array}$} & \multirow{2}{*}{$\frac{\text { Agreement }}{\text { Agree }}$} & \multirow{2}{*}{$\frac{\text { Answer options (score) }}{\text { Strongly agree }(3)}$} & \multicolumn{2}{|c|}{ Aggregated \% (n)/50 } & \multirow{2}{*}{$\frac{\mathbf{P}}{0.0046}$} \\
\hline & & & $6 \%$ & $70 \%(35)$ & \\
\hline & & Agree (18) & $36 \%$ & & \\
\hline & & Somewhat agree (14) & $28 \%$ & & \\
\hline & Disagree & Somewhat disagree (7) & $14 \%$ & $30 \%(15)$ & \\
\hline & & Disagree (7) & $14 \%$ & & \\
\hline & & Strongly disagree (1) & $2 \%$ & & \\
\hline \multirow{6}{*}{$\begin{array}{l}\text { The reminder helped remind me } \\
\text { to work with the patient on IS }\end{array}$} & Agree & Strongly agree (6) & $12 \%$ & $70 \%(35)$ & 0.0046 \\
\hline & & Agree (8) & $16 \%$ & & \\
\hline & & Somewhat agree (21) & $42 \%$ & & \\
\hline & Disagree & Somewhat disagree (7) & $14 \%$ & $30 \%(15)$ & \\
\hline & & Disagree (8) & $16 \%$ & & \\
\hline & & Strongly disagree (0) & $0 \%$ & & \\
\hline \multirow{6}{*}{$\begin{array}{l}\text { Overall, I found the reminder } \\
\text { to be helpful }\end{array}$} & Agree & Strongly agree (1) & $2 \%$ & $72 \%(36)$ & 0.0018 \\
\hline & & Agree (13) & $26 \%$ & & \\
\hline & & Somewhat agree (22) & $44 \%$ & & \\
\hline & Disagree & Somewhat disagree (7) & $14 \%$ & $28 \%(14)$ & \\
\hline & & Disagree (6) & $12 \%$ & & \\
\hline & & Strongly disagree (1) & $2 \%$ & & \\
\hline \multirow{6}{*}{$\begin{array}{l}\text { Overall, the reminder reduced } \\
\text { the amount of time } \\
\text { I spent educating or reminding } \\
\text { patients to use their IS }\end{array}$} & Agree & Strongly agree $(0)$ & $0 \%$ & $52 \%(34)$ & 0.7772 \\
\hline & & Agree (8) & $16 \%$ & & \\
\hline & & Somewhat agree (18) & $36 \%$ & & \\
\hline & Disagree & Somewhat disagree (18) & $36 \%$ & $48 \%(16)$ & \\
\hline & & Disagree (6) & $12 \%$ & & \\
\hline & & Strongly disagree $(0)$ & $0 \%$ & & \\
\hline
\end{tabular}

quently enough $(84.31 \% ; 43 / 51, \mathrm{p}<0.001)$, and who do not know when to use their IS (80.39\%; 41/51, p < 0.001) (Table 4).

Nurses announced that the SpiroTimer ${ }^{\mathrm{TM}}$ should become part of routine patient care $178 \%$; $39 / 50, \mathrm{p}<0.001)$. They felt that they would use the SpiroTimer ${ }^{\mathrm{TM}}$ with all their patients $(82 \%$; $41 / 50, p<0.001)$ and that they would recommend the SpiroTimer ${ }^{\mathrm{TM}}$ to a colleague $(74 \%$; $37 / 50, \mathrm{p}<$ 0.001) (Table 5).

\section{Discussion}

Through a survey of nurse users, this investigation evaluated human factors and usability of SpiroTimer ${ }^{\mathrm{TM}}$, a novel, clinically proven, use-tracking IS reminder. Overall, the nurses reported the SpiroTimer ${ }^{\mathrm{TM}}$ improved IS compliance and effectiveness; patient engagement in their own care; and nurses' attention to incentive spirometry while reducing the nurses' reminding efforts. Ultimately, the nurses would use the SpiroTimer ${ }^{\mathrm{TM}}$ with all their patients, recommend it to colleagues, and believe it should become a standard of care.

Human factors and usability engineering are paramount for successful implementation and adoption of a new medical device. Formative evaluations are critical in order to reduce factors that hinder device adoption $[8,9]$. Factors such as workload, alarm fatigue, and difficulty need to be addressed in the engineering of medical devices to avoid contribution to postoperative complications [10]. Alarming fatigue and workload increase due to too many clinically irrelevant alerts, and this can be thwarted by proper signal quality considerations and education of the healthcare providers [11]. These are just two examples of how usability engineering can impact device adoption. The SpiroTimer ${ }^{\mathrm{TM}}$ trial run has laid a threshold for formative evaluations of the device, and its 
Table 4. SpiroTimer ${ }^{\mathrm{TM}}$ usability and human factors

\begin{tabular}{|c|c|c|c|}
\hline The reminder directly addresses (mark all that apply): & $\%$ Yes $(\mathbf{n}) / 51$ & $\%$ No $(\mathbf{n}) / 51$ & $\mathbf{P}$ \\
\hline Patients forgetting to use their ISs & $96.08 \%(49)$ & $3.92 \%(2)$ & $<0.001$ \\
\hline Patients not knowing when to use their ISs & $80.39 \%(41)$ & $19.61 \%(10)$ & $<0.001$ \\
\hline Patients not understanding how to use their ISs & $15.69 \%(8)$ & $84.31 \%(43)$ & $<0.001$ \\
\hline Patients not using their ISs frequently enough & $84.31 \%(43)$ & $15.69 \%(8)$ & $<0.001$ \\
\hline Patients not using their ISs effectively & $21.57 \%(11)$ & $78.43 \%(40)$ & $<0.001$ \\
\hline Patients not using their ISs long enough & $27.45 \%(14)$ & $72.55 \%(37)$ & 0.0012 \\
\hline Providers not having enough time to work with patients on IS use & $39.22 \%(20)$ & $60.78 \%(31)$ & 0.1234 \\
\hline
\end{tabular}

IS - incentive spirometry

Table 5. Nurse user's conclusions on SpiroTimer ${ }^{\mathrm{TM}}$

\begin{tabular}{|c|c|c|c|c|c|}
\hline \multirow{3}{*}{$\begin{array}{l}\text { The reminder should become } \\
\text { part of routine patient care }\end{array}$} & \multirow{2}{*}{$\frac{\text { Agreement }}{\text { Agree }}$} & \multirow{2}{*}{$\begin{array}{c}\text { Answer options (score) } \\
\text { Strongly agree }(0)\end{array}$} & \multicolumn{2}{|c|}{ Aggregated \% (n)/50 } & \multirow{2}{*}{$\frac{\mathbf{P}}{<0.001}$} \\
\hline & & & $0 \%$ & $78 \%(39)$ & \\
\hline & & Agree (18) & $36 \%$ & & \\
\hline & & Somewhat agree (21) & $42 \%$ & & \\
\hline & Disagree & Somewhat disagree (5) & $10 \%$ & $22 \%(11)$ & \\
\hline & & Disagree (4) & $8 \%$ & & \\
\hline & & Strongly disagree (2) & $4 \%$ & & \\
\hline \multirow{6}{*}{$\begin{array}{l}\text { I would use the reminder } \\
\text { with my patients }\end{array}$} & Agree & Strongly agree (1) & $2 \%$ & $82 \%(41)$ & $<0.001$ \\
\hline & & Agree (19) & $38 \%$ & & \\
\hline & & Somewhat agree (21) & $42 \%$ & & \\
\hline & Disagree & Somewhat disagree (7) & $14 \%$ & $18 \%(9)$ & \\
\hline & & Disagree (2) & $4 \%$ & & \\
\hline & & Strongly disagree (0) & $0 \%$ & & \\
\hline \multirow{6}{*}{$\begin{array}{l}\text { I would recommend } \\
\text { the reminder to a colleague }\end{array}$} & Agree & Strongly agree (1) & $2 \%$ & $74 \%(37)$ & $<0.001$ \\
\hline & & Agree (16) & $32 \%$ & & \\
\hline & & Somewhat agree (20) & $40 \%$ & & \\
\hline & Disagree & Somewhat disagree (8) & $16 \%$ & $26 \%(13)$ & \\
\hline & & Disagree (2) & $4 \%$ & & \\
\hline & & Strongly disagree (3) & $6 \%$ & & \\
\hline
\end{tabular}

alarm capability. Building the next generation of SpiroTimer ${ }^{\mathrm{TM}}$ will incorporate all factors that would otherwise bar the adoption of the device.

The nurses around the country in this investigation shared similar views on IS, IS noncompliance as a problem, need for compliance improvement, and reasons for poor compliance [5]. This study's sample may reflect the views of a larger user population.

On the other hand, this study has its limitations. As a survey study, this investigation is subject to the weaknesses of surveys. However, it was able to achieve a $100 \%$ response rate and therefore, can reflect the whole population of nurses who have clinically interacted with the SpiroTimer $^{\mathrm{TM}}$ to date. Although surveys represent subjective data, the nature of human factors and usability is based on human-perceived interface. Future SpiroTimer ${ }^{\mathrm{TM}}$ human factor investigations may evaluate different groups of users (e.g. respiratory therapists, nursing aides, patients, and patient families) in various clinical settings.

Based on human factors feedback from intended users in an intended environment, the SpiroTimer $^{\mathrm{TM}}$ has the potential to be usable and effective. 


\section{Conflict of interest}

AE receives book editor royalties from Springer, Wolters Kluwer, Johns Hopkins University Press. He is listed as an inventor on the patent application US Application US20180000379A1, from which he has received no money or financial benefit from the patent application.

\section{References:}

1. Eltorai AEM, Baird GL, Pangborn J, et al. Financial impact of incentive spirometry. Inquiry. 2018; 55: 46958018794993, doi: 10.1177/0046958018794993, indexed in Pubmed: 30175643.

2. Martin TJ, Eltorai AS, Dunn R, et al. Clinical management of rib fractures and methods for prevention of pulmonary complications: A review. Injury. 2019; 50(6): 1159-1165, doi: 10.1016/j.injury.2019.04.020, indexed in Pubmed: 31047683.

3. Eltorai AEM, Szabo AL, Antoci V, et al. Clinical effectiveness of incentive spirometry for the prevention of postoperative pulmonary complications. Respir Care. 2018; 63(3): 347-352, doi: 10.4187/respcare.05679, indexed in Pubmed: 29279365.

4. Chen J, Eltorai AEM. Incentive spirometry after lung resection: the importance of patients' adherence. Ann Thorac Surg. 2019; 107(3): 985, doi: 10.1016/j.athoracsur.2018.08.032, indexed in Pubmed: 30312611.
5. Eltorai AEM, Baird GL, Eltorai AS, et al. Incentive spirometry adherence: a national survey of provider perspectives. Respir Care. 2018; 63(5): 532-537, doi: 10.4187/respcare.05882, indexed in Pubmed: 29362219.

6. Eltorai AEM, Baird GL, Eltorai AS, et al. Effect of an incentive spirometer patient reminder after coronary artery bypass grafting: a randomized clinical trial. JAMA Surg. 2019; 154(7): 579-588, doi: 10.1001/jamasurg.2019.0520, indexed in Pubmed: 30969332.

7. Center for Devices and Radiological Health. (n.d.). Human Factors and Medical Devices. Available online: www.fda.gov/medical-devices/device-advice-comprehensive-regulatory-assistance/human-factors-and-medical-devices. [Last accessed at: 03.09.2020].

8. Janice (Ginny) Redish, Randolph G. Bias, Robert Bailey, Rolf Molich, Joe Dumas, and Jared M. Spool. 2002. Usability in practice: formative usability evaluations - evolution and revolution. In CHI '02 Extended Abstracts on Human Factors in Computing Systems (CHI EA '02). Association for Computing Machinery, New York, NY, USA, 885-890. DOI:https://doi org/10. 1145; 506443: 506647, doi: 10.1145/506443.506647.

9. Borowski M, Görges M, Fried R, et al. Medical device alarms. Biomed Tech (Berl). 2011; 56(2): 73-83, doi: 10.1515/ BMT.2011.005, indexed in Pubmed: 21366502.

10. Branaghan RJ. Human factors in medical device design: methods, principles, and guidelines. Crit Care Nurs Clin North Am. 2018; 30(2): 225-236, doi: 10.1016/i.cnc.2018.02.005, indexed in Pubmed: 29724441.

11. North B. The growing role of human factors and usability engineering for medical devices. What's required in the new regulatory landscape. 2015. 